\title{
Thiazolidinone CFTR inhibitor identified by high-throughput screening blocks cholera toxin-induced intestinal fluid secretion
}

\author{
Tonghui Ma, ${ }^{1}$ Jay R. Thiagarajah, ${ }^{1}$ Hong Yang, ${ }^{1}$ Nitin D. Sonawane, ${ }^{1}$ Chiara Folli, ${ }^{2}$ \\ Luis J.V. Galietta, ${ }^{2}$ and A.S. Verkman ${ }^{1}$ \\ ${ }^{1}$ Department of Medicine, and Department of Physiology, Cardiovascular Research Institute, University of California, \\ San Francisco, San Francisco, California, USA \\ ${ }^{2}$ Laboratorio di Genetica Molecolare, Istituto Giannina Gaslini, Genova, Italy
}

\begin{abstract}
Secretory diarrhea is the leading cause of infant death in developing countries and a major cause of morbidity in adults. The cystic fibrosis transmembrane conductance regulator (CFTR) protein is required for fluid secretion in the intestine and airways and, when defective, causes the lethal genetic disease cystic fibrosis. We screened 50,000 chemically diverse compounds for inhibition of cAMP/flavone-stimulated $\mathrm{Cl}^{-}$transport in epithelial cells expressing CFTR. Six CFTR inhibitors of the 2-thioxo-4-thiazolidinone chemical class were identified. The most potent compound discovered by screening of structural analogs, CFTR inh -172 , reversibly inhibited CFTR short-circuit current in less than 2 minutes in a voltage-independent manner with $K_{\mathrm{I}}$ approximately $300 \mathrm{nM}$. CFTR $\mathrm{inh}-172$ was nontoxic at high concentrations in cell culture and mouse models. At concentrations fully inhibiting CFTR, CFTR inh-172 did not prevent elevation of cellular cAMP or inhibit non-CFTR $\mathrm{Cl}^{-}$ channels, multidrug resistance protein-1 (MDR-1), ATP-sensitive $\mathrm{K}^{+}$channels, or a series of other transporters. A single intraperitoneal injection of CFTR $_{\text {inh }}-172(250 \mu \mathrm{g} / \mathrm{kg})$ in mice reduced by more than $90 \%$ cholera toxin-induced fluid secretion in the small intestine over 6 hours. Thiazolidinone CFTR inhibitors may be useful in developing large-animal models of cystic fibrosis and in reducing intestinal fluid loss in cholera and other secretory diarrheas.
\end{abstract}

J. Clin. Invest. 110:1651-1658 (2002). doi:10.1172/JCI200216112.

\section{Introduction}

The cystic fibrosis transmembrane conductance regulator (CFTR) protein is a cAMP-activated $\mathrm{Cl}^{-}$channel expressed in epithelial cells in mammalian airways, intestine, pancreas, and testis. The hereditary lethal disease cystic fibrosis (CF) is caused by mutations in CFTR. Observations in human CF patients and CF mouse models indicate the functional importance of CFTR in intestinal and pancreatic fluid transport, as well as in male fertility $(1,2)$. However, the mechanisms remain unclear by which defective CFTR produces airway disease, which is the principal cause of morbidity and mortality in CF (3). Major difficulties in understanding airway disease in CF include the inadequacy of CF mouse models, which manifest little or no airway

Received for publication June 7, 2002, and accepted in revised form September 24, 2002.

Address correspondence to: Alan S. Verkman, 1246 Health Sciences East Tower, Cardiovascular Research Institute, University of California, San Francisco, San Francisco, California 94143-0521, USA. Phone: (415) 476-8530; Fax: (415) 665-3847; E-mail: verkman@itsa.ucsf.edu.

Conflict of interest: The authors have declared that no conflict of interest exists.

Nonstandard abbreviations used: cystic fibrosis transmembrane conductance regulator (CFTR); cystic fibrosis (CF); Fischer rat thyroid (FRT); multidrug resistance protein-1 (MDR-1). disease, the lack of large-animal models of $\mathrm{CF}$, and the limited availability of human CF airways that have not been damaged by chronic infection and inflammation. High-affinity, CFTR-selective inhibitors have not been available to study airway disease mechanisms in CF or to create the CF phenotype in large-animal models.

In addition to pharmacological creation of the CF phenotype, high-affinity CFTR inhibitors have potential clinical applications in the therapy of secretory diarrheas and cystic kidney disease, and in inhibiting male fertility. The compounds diphenylamine-2-carboxylate (DPC) and 5-nitro-2(3-phenylpropyl-amino)benzoate (NPPB) inhibit CFTR at high concentrations but are nonspecific in their inhibitory action (4-6). The best CFTR inhibitor available for electrophysiological and other cell-based studies, glibenclamide, is generally used at concentrations of greater than $100 \mu \mathrm{M}(7,8)$, at which it also inhibits other $\mathrm{Cl}^{-}$transporters as well as $\mathrm{K}^{+}$ channels (9-11). We postulated that small-molecule, high-affinity CFTR inhibitors may exist, based on the availability of potent inhibitors for some other ion transporters, as well as the demonstrated sensitivity of $\mathrm{CFTR} \mathrm{Cl} \mathrm{Cl}^{-}$conductance to small sequence changes in mutagenesis experiments.

The purpose of this study was to identify and characterize inhibitors of $\mathrm{CFTR} \mathrm{Cl}^{-}$channel function. Because of the limited information about CFTR structure and 
the inadequacy of available inhibitors as lead compounds, we screened a collection of diverse druglike compounds using a cell-based fluorescence assay developed in our laboratory (12-15). The high-throughput screening assay was designed to identify CFTR inhibitors that interact directly with CFTR. Several small-molecule CFTR inhibitors were identified that belonged to a novel chemical class. The best inhibitor identified by screening of structural analogs was subject to electrophysiological, mechanistic, and toxicological analyses and was shown to have efficacy in a mouse model of cholera toxin-induced secretory diarrhea.

\section{Methods}

Cell lines, mice, and compounds. Fischer rat thyroid (FRT) cells coexpressing human wild-type CFTR and the halide indicator YFP-H148Q were generated as described previously (14). Cells were plated in 96-well black-walled microplates (Corning-Costar Corp., Corning, New York, USA) at a density of 20,000 cells per well in Coon's modified F12 medium supplemented with $5 \%$ FCS, $2 \mathrm{mM}$ L-glutamine, $100 \mathrm{U} / \mathrm{ml}$ penicillin, and $100 \mu \mathrm{g} / \mathrm{ml}$ streptomycin. Assays were done at 48 hours after plating, at which time cells were just confluent ( 40,000 cells per well). Initial screening was done using a diverse collection of 50,000 druglike compounds from ChemBridge Research Laboratories (San Diego, California, USA), obtained as 10-mM stock solutions in DMSO and diluted to $1 \mathrm{mM}$ in 96-well microplates. Structure-activity analysis was done on analogs purchased from ChemBridge Research Laboratories and ChemDiv (San Diego, California, USA). Wild-type and CF ( $\triangle$ F508 homozygous mutant) mice were bred by the CF Animal Core facility at the University of California, San Francisco (UCSF). Animal protocols were approved by the UCSF Committee on Animal Research.

Synthesis of 2-thioxo-4-thiazolidinone analogs. Synthesis of CFTR $_{\text {inh-172 (see Figure 1c) and analogs with different }}$ positions of the trifluoromethyl and carboxy substituents was accomplished by Knoevenagel condensation of 2-thioxo-3-[a-trifluoromethylphenyl]-4-thiazolidinone $(a=2,3$, or 4$)$ with $b$-carboxybenzaldehyde $(b=2,3$, or 4$)$ in the presence of piperidine. Precipitates were filtered, washed with ethanol, dried, and recrystallized two to three times from ethanol to give bright yellow crystals (70-85\% yields). Structures were confirmed by ${ }^{1} \mathrm{H}-\mathrm{NMR}$. Purity was greater than $99 \%$ as judged by TLC and HPLC.

Screening procedures. Assays were done using a customized screening system (Beckman Coulter Inc., Indianapolis, Indiana, USA) consisting of a 3-meter robotic arm, $\mathrm{CO}_{2}$ incubator, plate washer, liquid-handling workstation, bar code reader, delidding station, and two FLUOstar fluorescence platereaders (BMG Labtechnologies, Durham, North Carolina, USA), each equipped with two syringe pumps and HQ500/20X $(500 \pm 10 \mathrm{~nm})$ excitation and HQ535/30M $(535 \pm 15$ $\mathrm{nm}$ ) emission filters (Chroma, Brattleboro, Vermont,
USA) (details in ref. 15). The robotic system was integrated using SAMI version 3.3 software (Beckman Coulter Inc.) modified for two platereaders. Custom software was written in Microsoft VBA (Visual Basic for Applications) to compute base-line-subtracted, normalized fluorescence slopes (giving halide influx rates) from stored data files.

We set up the assay by loading the incubator $\left(37^{\circ} \mathrm{C}\right.$, $90 \%$ humidity, $5 \% \mathrm{CO}_{2}$ ) with 40-60 96-well plates containing the FRT cells, and loading a carousel with 96well plates containing test compounds and disposable plastic pipette tips. To initiate the assay, each well of a 96-well plate was washed three times in PBS (300 $\mu \mathrm{l} /$ wash), leaving $50 \mu \mathrm{l} \mathrm{PBS}$. Ten microliters of a CFTRactivating cocktail $(5 \mu \mathrm{M}$ forskolin, $100 \mu \mathrm{M}$ IBMX [Sigma-Aldrich, St. Louis, Missouri, USA], $25 \mu \mathrm{M}$ apigenin in PBS) was added, and after 5 minutes one test compound ( $0.5 \mu \mathrm{l}$ of $1 \mathrm{mM}$ DMSO solution) was added to each well to give $10 \mu \mathrm{M}$ final concentration. After 10 minutes, 96-well plates were transferred to a platereader for fluorescence assay. We assayed each well individually for CFTR-mediated $\mathrm{I}^{-}$transport by recording fluorescence continuously (200 ms per point) for 2 seconds (base line) and then for 12 seconds after rapid ( $<0.5$ seconds) addition of $165 \mu \mathrm{l}$ of isosmolar PBS in which $137 \mathrm{mM} \mathrm{Cl}^{-}$was replaced by $\mathrm{I}^{-}$.

Assays of intracellular [cAMP], phosphatase, and toxicity. [cAMP] and phosphatase assays were done as reported previously (14). Cell toxicity was assayed by the dihydrorhodamine method at 24 hours after cell incubation with $0-1,000 \mu \mathrm{M}$ inhibitor. Animal toxicity was assessed by measurement of serum chemistries and hematology (UCSF Clinical Laboratory) in mice at 5 days after daily intraperitoneal injections with $0-1,000 \mu \mathrm{g} / \mathrm{kg}$ inhibitor.

MDR-1 activity. We evaluated multidrug resistance protein-1 (MDR-1) activity by measuring ${ }^{3} \mathrm{H}$-vincristine accumulation in an immortalized human tracheal cell line, 9HTEo-/Dx, in which the endogenous expression of MDR-1 was upregulated by selection in increasing concentrations of doxorubicin (16). Cells were seeded in 24-well microplates (200,000 cells per well). After 48 hours, cells were washed with a solution containing (in $\mathrm{mM}) 130 \mathrm{NaCl}, 2 \mathrm{KCl}, 1 \mathrm{KH}_{2} \mathrm{PO}_{4}, 2 \mathrm{CaCl}_{2}, 2 \mathrm{MgCl}_{2}, 10$ Na-HEPES ( $\mathrm{pH} 7.3$ ), and 10 glucose, and incubated for 1 hour at $37^{\circ} \mathrm{C}$ with $200 \mu \mathrm{l}$ of the same solution containing ${ }^{3} \mathrm{H}$-vincristine $(0.7 \mu \mathrm{M} ; 1 \mu \mathrm{Ci} / \mathrm{ml})$. Cells were then washed three times with ice-cold solution and lysed in $0.25 \mathrm{M} \mathrm{NaOH}$. Vincristine content was determined by scintillation counting.

Short-circuit current. Snapwell inserts containing CFTR-expressing FRT cells or human bronchial epithelial cells were mounted in an Ussing chamber system. For FRT cells, the hemichambers were filled with $5 \mathrm{ml}$ of $75 \mathrm{mM} \mathrm{NaCl}$ and $75 \mathrm{mM} \mathrm{Na}$ gluconate (apical) and $150 \mathrm{mM} \mathrm{NaCl}$ (basolateral) ( $\mathrm{pH} 7.3$ ), and the basolateral membrane was permeabilized with $250 \mu \mathrm{g} / \mathrm{ml}$ amphotericin B $(14,15)$. For bronchial epithelial cells and T84 cells, both hemichambers contained a Krebs bicarbonate solution (15). Hemichambers were con- 
tinuously bubbled with air (FRT cells) or $5 \% \mathrm{CO}_{2}$ in air (bronchial and T84 cells) and maintained at $37^{\circ} \mathrm{C}$. Short-circuit current was recorded continuously using a DVC-1000 voltage clamp (World Precision Instruments, Sarasota, Florida, USA) with $\mathrm{Ag} / \mathrm{AgCl}$ electrodes and $1 \mathrm{M} \mathrm{KCl}$ agar bridges.

Patch-clamp analysis of $\mathrm{Cl}^{-}$channel activity. Membrane current was measured in a whole-cell configuration. For recordings of $\mathrm{Cl}^{-}$channels, the extracellular (bath) solution contained (in $\mathrm{mM}$ ) $150 \mathrm{NaCl}, 1 \mathrm{CaCl}_{2}, 1$ $\mathrm{MgCl}_{2}, 10$ glucose, 10 mannitol, and 10 TES (pH 7.4), and the intracellular (pipette) solution contained 120 $\mathrm{CsCl}, 1 \mathrm{MgCl}_{2}, 10$ TEA-Cl, 0.5 EGTA, $1 \mathrm{Mg}$-ATP, and 10 HEPES ( $\mathrm{pH}$ 7.3). CFTR was activated by forskolin (5 $\mu \mathrm{M})$ in the extracellular solution. The time course of membrane conductance was monitored in response to alternating voltage pulses of -100 and $+80 \mathrm{mV}$. At defined times the protocol was interrupted to generate current-voltage relationships (voltage pulses from -100 to $+100 \mathrm{mV}$ in $20-\mathrm{mV}$ increments). Volume-sensitive $\mathrm{Cl}^{-}$channels were activated by a hypotonic solution (extracellular $\mathrm{NaCl}$ decreased to $120 \mathrm{mM} \mathrm{NaCl} ; 250$ $\operatorname{mosM} / \mathrm{kg}$ ). Calcium-sensitive $\mathrm{Cl}^{-}$channels were activated in human bronchial epithelial cells by addition of $100 \mu \mathrm{M}$ UTP to the extracellular solution.

Patch-clamp analysis of ATP-sensitive $K^{+}$channels. Membrane potential was recorded in the pancreatic $\beta$ cell line INS-1, in which the extracellular (bath) solution contained (in mM): $130 \mathrm{NaCl}, 2 \mathrm{KCl}, 1 \mathrm{KH}_{2} \mathrm{PO}_{4}, 2 \mathrm{CaCl}_{2}, 2$ $\mathrm{MgCl}_{2}, 10 \mathrm{Na}$-HEPES (pH 7.3), and 10 glucose. The pipette contained (in $\mathrm{mM}$ ): $140 \mathrm{KCl}, 1 \mathrm{CaCl}_{2}, 2 \mathrm{mM}$ $\mathrm{MgCl}_{2}, 10$ EGTA, $0.5 \mathrm{Mg}$-ATP, and 10 K-HEPES (pH 7.3). After the whole-cell configuration was achieved, the amplifier was switched to current-clamp mode.

Intestinal fluid secretion and short-circuit current. In the first of three assays, fluid accumulation in ileal loops was measured $(17,18)$. Mice (age 8-10 weeks, body weight $25-35 \mathrm{~g}$ ) in a CD1 genetic background (or $\Delta$ F508 homozygous mice) were starved for 24 hours and anesthetized with intraperitoneal ketamine $(40 \mathrm{mg} / \mathrm{kg})$ and xylazine $(8 \mathrm{mg} / \mathrm{kg})$. Body temperature was maintained during surgery at $36-38^{\circ} \mathrm{C}$ using a heating pad. A small abdominal incision was made to expose the small intestine, and closed ileal loops (length $20-30 \mathrm{~mm}$ ) proximal to the cecum were isolated by sutures. Loops were injected with $100 \mu \mathrm{l}$ of PBS alone or PBS containing cholera toxin $(1 \mu \mathrm{g})$. In some experiments the inhibitor $(150$ $\mu \mathrm{g} / \mathrm{kg}$ ) was administered by intraperitoneal injection. The abdominal incision was closed with suture, and mice were allowed to recover from anesthesia. At 6 hours the mice were anesthetized, intestinal loops were exteriorized, and loop length and weight were measured after removal of mesentery and connective tissue.

In the sealed adult mouse model of secretory diarrhea, mice were gavaged with cholera toxin $(10 \mu \mathrm{g})$ in $0.1 \mathrm{ml}$ of $7 \%$ bicarbonate buffer (or buffer alone) using a orogastric feeding needle $(19,20)$. The four experimental groups were control (buffer alone), choleratreated, treated with cholera plus inhibitor $(250 \mu \mathrm{g} / \mathrm{kg}$ intraperitoneally 2 minutes before gavage), and treated with inhibitor alone. After 6 hours, mice were euthanized and the small intestine (from pylorus to cecum) was exteriorized and stripped of associated mesenteric and connective tissues. The intestine was weighed, then opened longitudinally to remove lumenal fluid (by blotting) and weighed again. Fluid accumulation was computed from the ratio of intestinal weight before to intestinal weight after lumenal fluid removal. For measurement of short-circuit current, strips of rat colon were isolated, stripped of muscle layers by blunt dissection, mounted in Ussing chambers (area $0.7 \mathrm{~cm}^{2}$ ), and bathed in oxygenated bicarbonate Ringer's solution containing $10 \mu \mathrm{M}$ indomethacin. Short-circuit current was measured after inhibition of $\mathrm{Na}^{+}$current by amiloride $(10 \mu \mathrm{M})$, followed by stimulation by forskolin $(20 \mu \mathrm{M})$ and subsequent inhibitor addition.

\section{Results}

The primary screen was designed to identify compounds that inhibited CFTR Cl- conductance by direct CFTR-inhibitor interaction. CFTR was prestimulated in CFTR-expressing FRT cells by an activating cocktail containing forskolin, IBMX, and apigenin (Figure 1a). The rationale for CFTR activation by multiple mechanisms (cAMP elevation, phosphodiesterase inhibition, and direct CFTR binding) was to identify inhibitors that blocked the CFTR $\mathrm{Cl}^{-}$transporting pathway directly rather than blocking a more proximal step(s) in the activation pathway. The FRT cells coexpressed a yellow fluorescent protein-based $\mathrm{Cl}^{-} / \mathrm{I}^{-}$sensor that provided a quantitative fluorescence read-out of inhibition potency $(12,13)$. After CFTR prestimulation and compound addition, cells were subjected to an inwardly directed $\mathrm{I}^{-}$ gradient to drive $\mathrm{I}^{-}$influx and produce decreasing fluorescence. Each assay consisted of recording of base-line fluorescence for 2 seconds, followed by 12 seconds of continuous recording of fluorescence after rapid addition of the solution containing $\mathrm{I}^{-}$. Compounds were tested separately at $10 \mu \mathrm{M}$ concentration in a 96-well format using a fully automated high-throughput screening apparatus (see Methods).

Figure $1 \mathrm{~b}$ shows representative curves from the primary screen of 50,000 compounds. As quantified from the slope of the decreasing fluorescence after $\mathrm{I}^{-}$addition, 49,993 compounds had no significant effect on the kinetics of I- influx ( $<10 \%$ decrease in slope). Seven compounds produced a small decrease in negative slope (10-52\%), nearly all of which had a similar core structure consisting of a 2-thioxo-4-thiazolidinone heterocycle with substituted phenylmethylene and phenyl moieties (Figure 1c, top). More than 250 analogs having thiazolidinone core structure were subsequently screened to identify the most potent CFTR inhibitors. Figure 1c (bottom) shows the most potent compound, 3-[(3trifluoromethyl)phenyl]-5-[(4-carboxyphenyl) methylene]-2-thioxo-4-thiazolidinone ( $\mathrm{CFTR}_{\text {inh-172), }}$ along with five analogs having lower inhibitory potencies. Inhibition required the 3-trifluoromethyl substitu- 

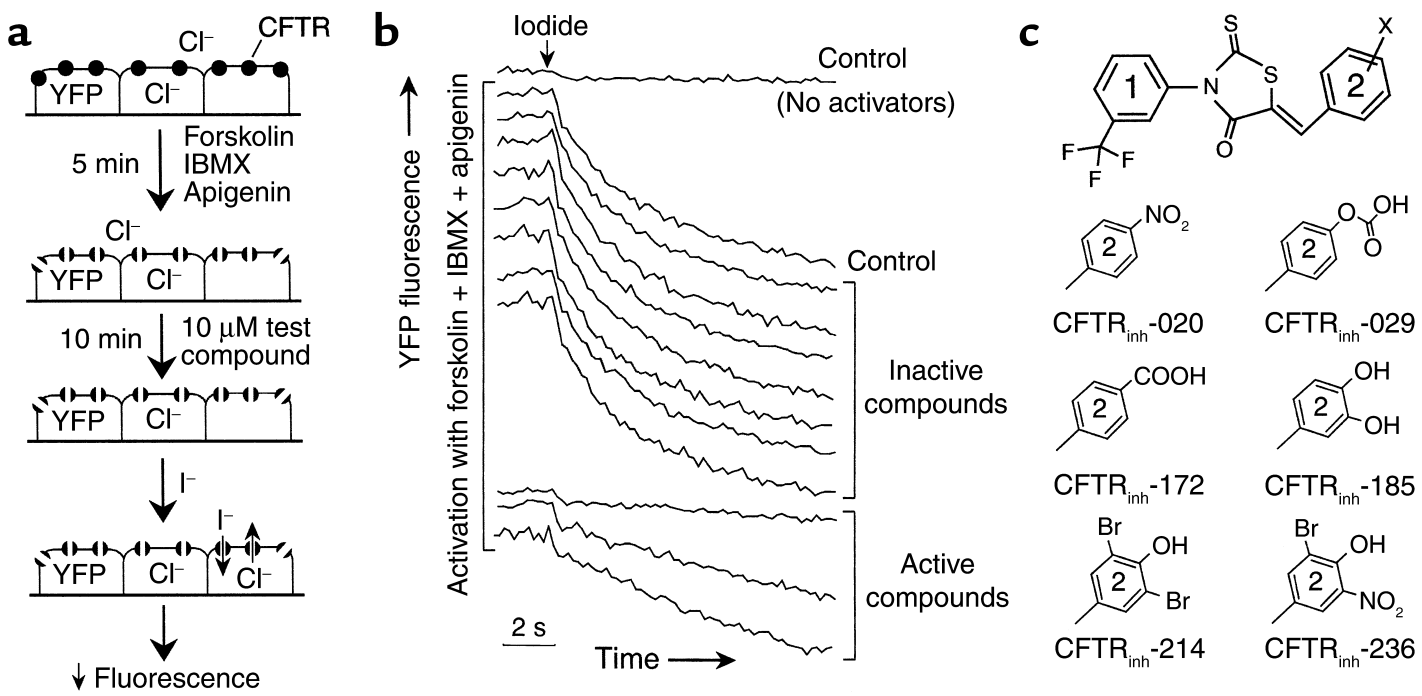

\begin{abstract}
Figure 1
Identification of CFTR inhibitors by high-throughput screening. (a) Schematic of screening approach. CFTR was maximally stimulated by multiple agonists in stably transfected epithelial cells coexpressing human CFTR and a yellow fluorescent protein (YFP) with fluorescence sensitive to $\mathrm{Cl}^{-} / \mathrm{I}^{-}$. After addition of test compound, $\mathrm{I}^{-}$influx was induced by adding an $\mathrm{I}^{-}$-containing solution. (b) Representative original fluorescence data from individual wells showing controls (no activators, no test compound) and test wells. (c) Top: Chemical structure of 2-thioxo-4-thiazolidinone CFTR inhibitors. Bottom: Structures of analogs having greatest CFTR inhibitory activity. Relative potencies were

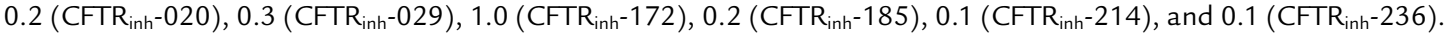

tion on ring 1 and a negative or polar substituent(s) on ring 2. Interestingly, the five-member heterocycle and trifluoromethyl substituent in $\mathrm{CFTR}_{\text {inh }}-172$ were present in several high-affinity CFTR activators that were identified recently by high-throughput screening (15). To examine the effect of ring position of the trifluoromethyl and carboxyl substituents, eight analogs of CFTR $_{\text {inh }}-172$ were synthesized in which the substituents were moved to each unique position on rings 1 (trifluoromethyl) and 2 (carboxy). Compared with CFTR $_{\text {inh }}-172$ (potency 1.0), the relative inhibitory potencies of the 3-[(a-trifluoromethyl)phenyl]-5-[(b-carboxyphenyl)methylene]-2-thioxo-4-thiazolidinone analogs were $0.69(a=2$, $b=2), 0.70(a=2, b=3), 0.66(a=2, b=4), 0.74(a=3, b=2)$, $0.90(a=3, b=3), 0.67(a=4, b=2), 0.64(a=4, b=3)$, and $0.56(a=4, b=4)$. As the most potent CFTR inhibitor, CFTR $_{\text {inh }}-172$ was further characterized.

Figure 2 a shows dose-inhibition data for $\mathrm{CFTR}_{\text {inh }}-172$ as determined by the fluorescence assay. Significant inhibition was seen at 0.3-0.6 $\mu \mathrm{M} \mathrm{CFTR}_{\text {inh-172. Fig- }}$ ure $2 \mathrm{~b}$ shows that inhibition by $\mathrm{CFTR}_{\text {inh }}-172$ was complete in approximately 10 minutes $\left(t_{1 / 2} 4\right.$ minutes) and was reversed after washout with $t_{1 / 2}$ approximately 5 minutes (inset). Figure $2 \mathrm{c}$ shows that $\mathrm{CFTR}_{\text {inh }}-172$ effectively inhibited CFTR activation by multiple types of agonists that were not included in the activating cocktail used for initial screening, including genistein, CPT-cAMP, 8-cyclopentyl-1,3dipropylxanthine (CPX), 8-methoxypsoralen (8-MPO), and the potent benzoflavone CFTR activator UCCF029 and the benzimidazolone CFTR activator UCCF853 (14). Also, CFTR inh -172 inhibited CFTR activation by four recently described CFTR activators
$\left(\mathrm{CFTR}_{\text {act }}-05,-09,-11\right.$, and -16 ; ref. 15$)$ that are structurally unrelated and probably activate CFTR by a direct interaction mechanism (not shown).

Electrophysiology was done to establish the inhibitory potency and specificity of $\mathrm{CFTR}_{\text {inh }}-172$. Figure $3 \mathrm{a}$ (left) shows the rapid, dose-dependent inhibition of short-circuit current in CFTR-expressing FRT cells with CFTR $_{\text {inh }}-172$ added to the solution bathing the apical cell surface. Figure 3a (right) shows the average doseinhibition relationships of CFTR inh $-172\left(K_{\mathrm{d}} \sim 300 \mathrm{nM}\right.$, Hill coefficient $\sim 1)$ and glibenclamide $\left(K_{\mathrm{d}} \sim 200 \mu \mathrm{M}\right)$ tested under identical conditions. Similar inhibitory potencies were found in cells that natively express wildtype CFTR, including T84 cells and primary cultures of human bronchial epithelial cells, as well as in transfected FRT cells expressing G551D-CFTR and $\Delta$ F508-CFTR (after low temperature correction) (not shown). For studies in bronchial cells, the $\mathrm{Na}^{+}$channel was blocked with amiloride so that base-line current is largely CFTRdependent. After maximal CFTR activation by a CPTcAMP, application of $\mathrm{CFTR}_{\text {inh }}-172$ from the apical side inhibited short-circuit current strongly (Figure 3b, left). CFTR $_{\text {inh }}-172$ was apparently less potent when added from the basolateral side (Figure 3b, right); this may be related to reduced access through the porous filter, or, less likely, to its differential permeability across the apical versus the basolateral plasma membranes or to compartmentation phenomena in epithelial cells.

Whole-cell membrane currents were measured by patch clamp in CFTR-expressing FRT cells (Figure 3c, left). Stimulation by $5 \mu \mathrm{M}$ forskolin produced a membrane current of $381 \pm 47 \mathrm{pA} / \mathrm{pF}(n=4)$ at $+100 \mathrm{mV}$ (total membrane capacitance $21 \pm 3 \mathrm{pF}$ ). The current- 

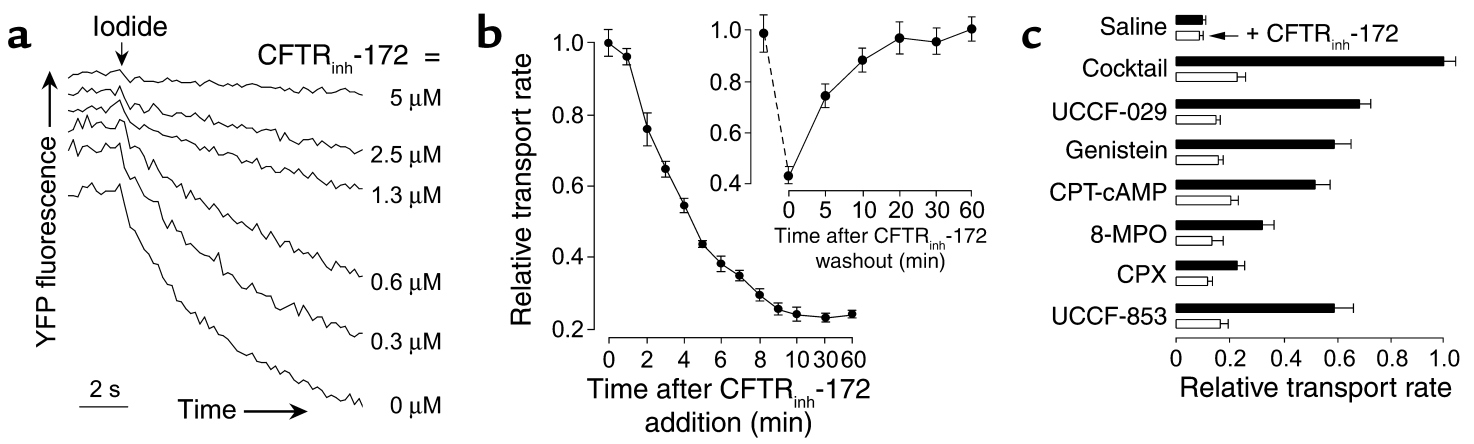

\section{Figure 2}

Characterization of CFTR inhibition by CFTR $_{\text {inh }}-172$. (a) CFTR functional assays as in Figure 1 b for indicated [CFTR inh -172$]$. (b) Time course of inhibition showing CFTR-mediated I- transport rates at different times after addition of $2 \mu \mathrm{M} \mathrm{CFTR}_{\text {inh }}-172$. Inset: Time course of inhibition reversal showing $\mathrm{I}^{-}$transport rates at different times after washout of $1 \mu \mathrm{M} \mathrm{CFTR} \mathrm{inh}-172$. Mean $\pm \mathrm{SE}$ is shown from three sets of experiments. (c) Inhibition of CFTR after stimulation by different agonists, including benzoflavone and benzimidazolone UCCF compounds (14), genistein, CPT-cAMP, 8-methoxypsoralen (8-MPO), and 8-cyclopentyl-1,3-dipropylxanthine (CPX) (all $50 \mu \mathrm{M})$ (SE; three sets of experiments). Black bars, agonist; white bars, agonist $+5 \mu \mathrm{M}$ CFTR inh $^{-172}$.

voltage relationship was linear, as expected for a pure CFTR current (Figure 3c, right). Extracellular perfusion with $2 \mu \mathrm{M} \mathrm{CFTR}_{\text {inh }}-172$ produced a rapid reduction in current at all membrane potentials, suggesting voltageindependent CFTR inhibition. The lack of voltagedependence of channel block was confirmed using a lower concentration of CFTR inh $-172(0.2 \mu \mathrm{M})$ to obtain about $50 \%$ inhibition (Figure $3 c$, right).

The specificity of CFTR inh -172 for inhibition of CFTR was studied. Two non-CFTR $\mathrm{Cl}^{-}$channels were studied. $\mathrm{CFTR}_{\text {inh- }}-172$ at $5 \mu \mathrm{M}$ did not inhibit $\mathrm{Ca}^{2+}$-activated $\mathrm{Cl}^{-}$ secretion produced by addition of UTP $(100 \mu \mathrm{M})$ to the apical bathing solution in polarized human bronchial epithelial cells (Figure 4a, left). Maximal UTP-dependent short-circuit currents were $9.9 \pm 0.5 \mu \mathrm{A} / \mathrm{cm}^{2}$ and
$10.0 \pm 0.2 \mu \mathrm{A} / \mathrm{cm}^{2}$ in the absence and presence of $\mathrm{CFTR}_{\text {inh }}-172$, respectively $(\mathrm{SE} ; n=4)$. CFTR inh -172 at 5 $\mu \mathrm{M}$ also did not block volume-activated $\mathrm{Cl}^{-}$currents elicited in FRT cells by extracellular perfusion with a $250 \mathrm{mosM} / \mathrm{kg}$ hypotonic solution (Figure $4 \mathrm{a}$, right).

The activity of a CFTR homolog, the ATP-binding cassette transporter MDR-1, was measured in 9HTEo/Dx cells, which overexpress MDR-1 (16). Vincristine accumulation, which is inversely related to active drug extrusion by MDR-1, was strongly increased by the MDR-1 inhibitor verapamil $(100 \mu \mathrm{M})$ (Figure $4 \mathrm{~b})$. CFTR $_{\text {inh }}-172(5 \mu \mathrm{M})$ did not affect vincristine accumulation and thus did not inhibit MDR-1. Another homolog of CFTR is the sulphonylurea receptor (SUR), which regulates the activity of ATP-sensitive $\mathrm{K}^{+}$

\section{Figure 3}

Electrophysiological analysis of CFTR inhibition. (a) Left: CFTR inh -172 inhibition of short-circuit current $\left(I_{s c}\right)$ in permeabilized FRT cells expressing human CFTR. CFTR was stimulated by $100 \mu \mathrm{M}$ CPTcAMP. Right: Dose-inhibition data for $\mathrm{CFTR}_{\text {inh-172 (circles) and }}$ glibenclamide (squares) (SE; $n=3$ sets of experiments). (b) CFTR inh $^{-172}$ inhibition of short-circuit current in primary culture of (nonpermeabilized) human bronchial epithelial cells. Inhibitor was added in apical bathing solution (left) or basolateral and then apical solutions (right). (c) Left: Whole-cell patch clamp of CFTR-expressing FRT cells showing membrane currents elicited at $+80 \mathrm{mV}$ (open circles) and $-100 \mathrm{mV}$ (filled circles). CFTR was stimulated by $5 \mu \mathrm{M}$ forskolin followed by addition of $2 \mu \mathrm{M}$ CFTR inh -172 . The alternate stimulation was interrupted (I-III) for application of graded membrane potentials (middle). Right: Current-voltage relationships under basal conditions (control, open circles), after forskolin stimulation (filled circles), and following addition of $0.2 \mu \mathrm{M}$ CFTR $_{\text {inh }}-172$ giving approximately $50 \%$ inhibition (open triangles). $I_{\mathrm{m}}$, membrane current; $V_{\mathrm{m}}$, membrane potential.
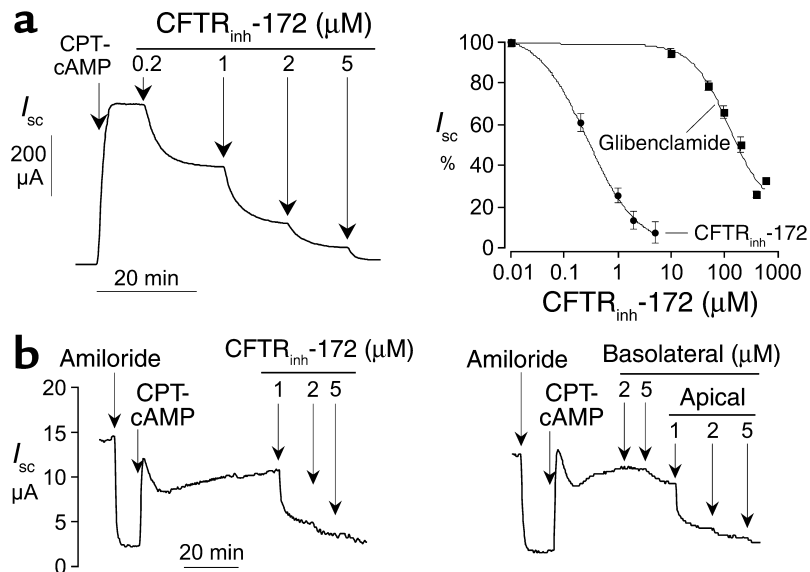

Amiloride Basolateral $(\mu \mathrm{M})$

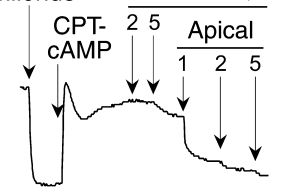

C
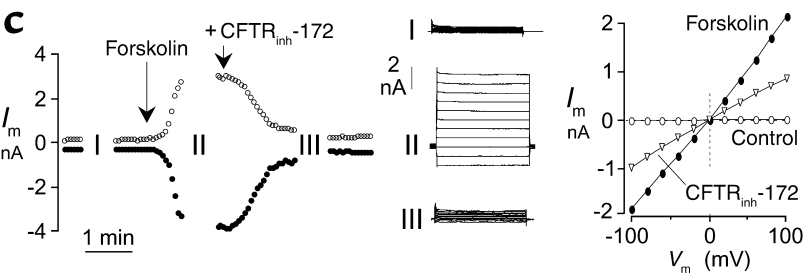
a
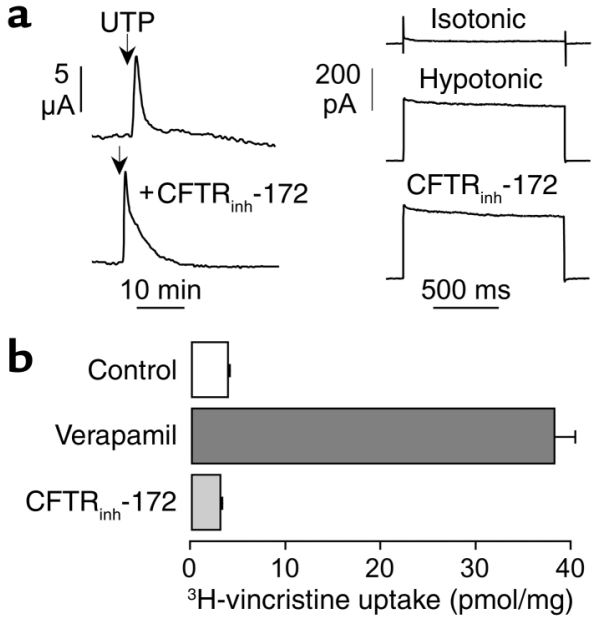

C

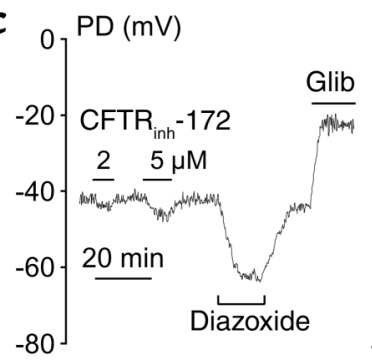

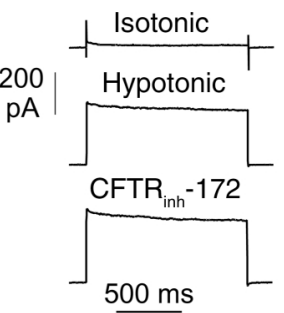

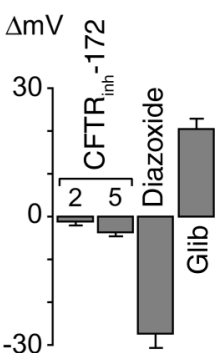

\section{Figure 4}

Specificity of CFTR inhibition by CFTR inh-172. (a) Alternative $\mathrm{Cl}^{-}$ channels. Left: UTP $(100 \mu \mathrm{M})$ stimulated $\mathrm{Ca}^{2+}$-dependent $\mathrm{Cl}^{-}$secretion measured in short-circuit current measurements on airway epithelial cells in the absence and presence of $5 \mu \mathrm{M} \mathrm{CFTR}$ inh -172 . Right: Volume-activated $\mathrm{Cl}^{-}$current (hypotonic $250 \mathrm{mosM} / \mathrm{kg}$ $\mathrm{H}_{2} \mathrm{O}$ ) measured in whole-cell patch-clamp experiments on FRT cells. Currents were recorded in the absence and presence of $5 \mu \mathrm{M}$ $\mathrm{CFTR}_{\text {inh }}-172$. (b) MDR- 1 activity. ${ }^{3} \mathrm{H}$-vincristine accumulation in 9HTEo-/Dx cells with upregulated MDR-1 expression. Intracellular vincristine was measured with and without verapamil $(100 \mu \mathrm{M})$ or CFTR $_{\text {inh-172 }}$ ( $\left.5 \mu \mathrm{M}\right)(\mathrm{SE} ; n=3)$. (c) ATP-sensitive $\mathrm{K}^{+}$channels. Left: Representative membrane potential recording from a pancreatic $\beta$ cell (INS-1) perfused extracellularly with $C F T R_{\text {inh }}-172$, diazoxide $(100 \mu \mathrm{M})$, and glibenclamide (glib; $10 \mu \mathrm{M})$. Right: Averaged changes in membrane potential $(\Delta \mathrm{mV})$ caused by indicated maneuvers $(\mathrm{SE} ; n=4)$. PD, potential difference.

channels (K-ATP channel; ref. 21). SUR1 is expressed in pancreatic $\beta$ cells, where it controls membrane potential and insulin release. Sulphonylureas like glibenclamide cause insulin release (and a hypoglycemic response) by blocking K-ATP channels and membrane depolarization. To determine whether CFTR $_{\text {inh }}-172$ also blocks K-ATP channels, membrane potential in a rat pancreatic $\beta$ cell line, INS-1, was measured (Figure 4c). In contrast to glibenclamide, which caused large membrane depolarization, $\mathrm{CFTR}_{\text {inh }}-172(2$ and $5 \mu \mathrm{M})$ did not depolarize membrane potential. CFTR inh -172 at $5 \mu \mathrm{M}$ caused a small hyperpolarization that was much less than that caused by the K-ATP channel activator diazoxide $(100 \mu \mathrm{M})$. Additional studies (not shown) indicated that $\mathrm{CFTR}_{\text {inh }}-172$ at $5 \mu \mathrm{M}$ did not block a water channel

(AQP1), a urea transporter (UT-B), an $\mathrm{Na}^{+} / \mathrm{H}^{+}$exchanger (NHE3), and $\mathrm{a} \mathrm{Cl}^{-} / \mathrm{HCO}_{3}{ }^{-}$exchanger (AE1).

Further analysis showed that $5 \mu \mathrm{M} \mathrm{CFTR}_{\text {inh }}-172 \mathrm{did}$ not affect cellular cAMP production or phosphatase activity. In FRT cells, basal cAMP content was $225 \pm 22$ $\mathrm{fmol} /$ well, which increased at 30 minutes after stimulation by $20 \mu \mathrm{M}$ forskolin to $1,290 \pm 190 \mathrm{fmol} /$ well (no inhibitor) and 1,140 $\pm 50\left(+\mathrm{CFTR}_{\text {inh }}-172\right)(n=3)$. As judged using the dihydrorhodamine assay, CFTR $_{\text {inh }}-172$ was nontoxic to FRT cells after 24 hours at concentrations up to $100 \mu \mathrm{M}$. In mice, intraperitoneal injection of $1,000 \mu \mathrm{g} / \mathrm{kg}$ CFTR $_{\text {inh }}-172$ daily for 7 days did not cause overt toxicity. Food and water intake were not diminished, and serum electrolyte concentrations, glucose, liver function indices, serum creatinine, amylase, and hematocrit were not changed. In addition, a single very large systemic dose of CFTR inh $-172(10 \mathrm{mg} / \mathrm{kg}) \mathrm{did}$ not cause overt toxicity.

The efficacy of CFTR inh -172 was tested in vivo using two assays of cholera toxin-induced intestinal fluid secretion, and in isolated intestine by short-circuit analysis. In the first assay, a series of closed loops of small intestine were created in vivo, and the lumens of alternate loops were injected with small volumes of saline or saline containing cholera toxin. Luminal fluid accumulation was determined after 6 hours. As seen visually, there was marked fluid accumulation and distention in cholera toxin-treated loops, whereas adjacent control (saline) loops remained empty (Figure 5a). A single administration of CFTR inh $-172(250 \mu \mathrm{g} / \mathrm{kg}$ intraperitoneally) prior to cholera toxin infusion effectively prevented fluid accumulation in the toxin-treated intestinal loops. Data from a series of experiments are summarized in Figure 5 b. CFTR inh -172 significantly reduced fluid secretion to that in saline control loops, whereas an inactive $\mathrm{CFTR}_{\text {inh }}-172$ analog did not inhibit fluid secretion. As suggested from previous data (22), cholera toxin-treated loops of intestine from homozygous $\Delta$ F508-CFTR mice also remained empty, indicating the involvement of CFTR in intestinal fluid secretion. In the second assay, intestinal fluid secretion was induced by oral administration of cholera toxin $(10$ $\mu \mathrm{g}$ ), and $\mathrm{CFTR}_{\text {inh }}-172$ was administered systemically. After 6 hours there was marked accumulation of fluid, as measured by weighing the entire small intestine. CFTR $_{\text {inh }}-172$ administration remarkably reduced intestinal fluid accumulation, as seen visually and quantified by the ratio of intestinal weight before versus after luminal fluid removal (Figure 5c).

Figure $5 \mathrm{~d}$ shows $\mathrm{CFTR}_{\mathrm{inh}}-172$ inhibition of short-circuit current across intact rat colonic mucosa. After inhibition of $\mathrm{Na}^{+}$current by amiloride, forskolin produced a prompt increase in short-circuit current. CFTR inh -172 added to the mucosal solution inhibited short-circuit current with greater efficacy than CFTR $_{\text {inh }}-172$ added to the serosal solution; this may be related to impaired access to colonic epithelial cells through the residual submucosal tissue. Addition of $5 \mu \mathrm{M} \mathrm{CFTR}_{\text {inh }}-172$ to the mucosal solution alone reduced short-circuit cur- 
rent by more than $80 \%$ (not shown). These results provide electrophysiological evidence for $\mathrm{CFTR} \mathrm{Cl}^{-}$channel inhibition by CFTR $_{\text {inh }}-172$ in intestine.

\section{Discussion}

The purpose of this study was to identify high-affinity CFTR inhibitors for application to studies of CF disease mechanisms and to the treatment of secretory diarrheas. We screened a collection of small, drug-like compounds using an assay designed to identify CFTR inhibitors that interact directly with CFTR. Since multiple CFTR activators that work on different activating pathways were included, we reasoned that any inhibitory compounds should interact at or near the CFTR $\mathrm{Cl}^{-}$ transporting pathway. The primary screening of 50,000 diverse compounds identified a small set of putative inhibitors of the 2-thioxo-4-thiazolidinone compound class. These compounds are unrelated structurally to known CFTR activators and to the CFTR inhibitors diphenylamine-2-carboxylate (DPC), 5-nitro-2(3phenylpropyl-amino)benzoate (NPPB), and glibenclamide. The most potent CFTR inhibitor identified by screening of a library of structural analogs had a $K_{\mathrm{I}}$ of about $300 \mathrm{nM}$ for inhibition of $\mathrm{Cl}^{-}$current in human airway cells. Inhibition was rapid, reversible, and voltage-independent. At concentrations at which $\mathrm{CFTR} \mathrm{Cl}^{-}$ conductance was nearly completely blocked, the inhibitor did not inhibit other $\mathrm{Cl}^{-}$channels, MDR-1, ATP-sensitive $\mathrm{K}^{+}$channels, or other transporters. The inhibitor was nontoxic in mice, where a systemically administered dose 100 times that inhibiting cholera toxin-induced fluid secretion was well tolerated.

The new class of CFTR inhibitors identified here may be useful for development of drugs to block intestinal fluid secretion in cholera and other secretory diarrheas such as AIDS-related diarrhea and traveler's (Escherichia coli) diarrhea. Secretory diarrhea is the largest cause of infant death in developing countries, with about 5 million deaths annually (23). Several studies, including those in CF mice, suggest that CFTR is the final common pathway for intestinal $\mathrm{Cl}^{-}$ (and thus fluid) secretion in response to various agonists $(22,24,25)$. The mouse models of intestinal fluid secretion used here indicate that CFTR inhibition by systemic administration of the inhibitor at a nontoxic dose effectively blocked intestinal fluid secretion induced by cholera toxin. Inhibitor testing in larger animal models is needed, as is analysis of stool output using live Vibrio cholerae (26).

The pharmacological creation of the CF phenotype in human tissues and animal models may facilitate elucidation of the mechanism by which defective CFTR causes lung disease and clinical morbidity in CF. There is increasing evidence that defective fluid and macromolecular secretion by airway submucosal glands leads to impaired mucociliary function and bacterial clearance in CF; however, functional studies in human airway glands have been restricted to severely diseased airways obtained at the time of lung transplantation (27). Acute CFTR inhibition should permit determination
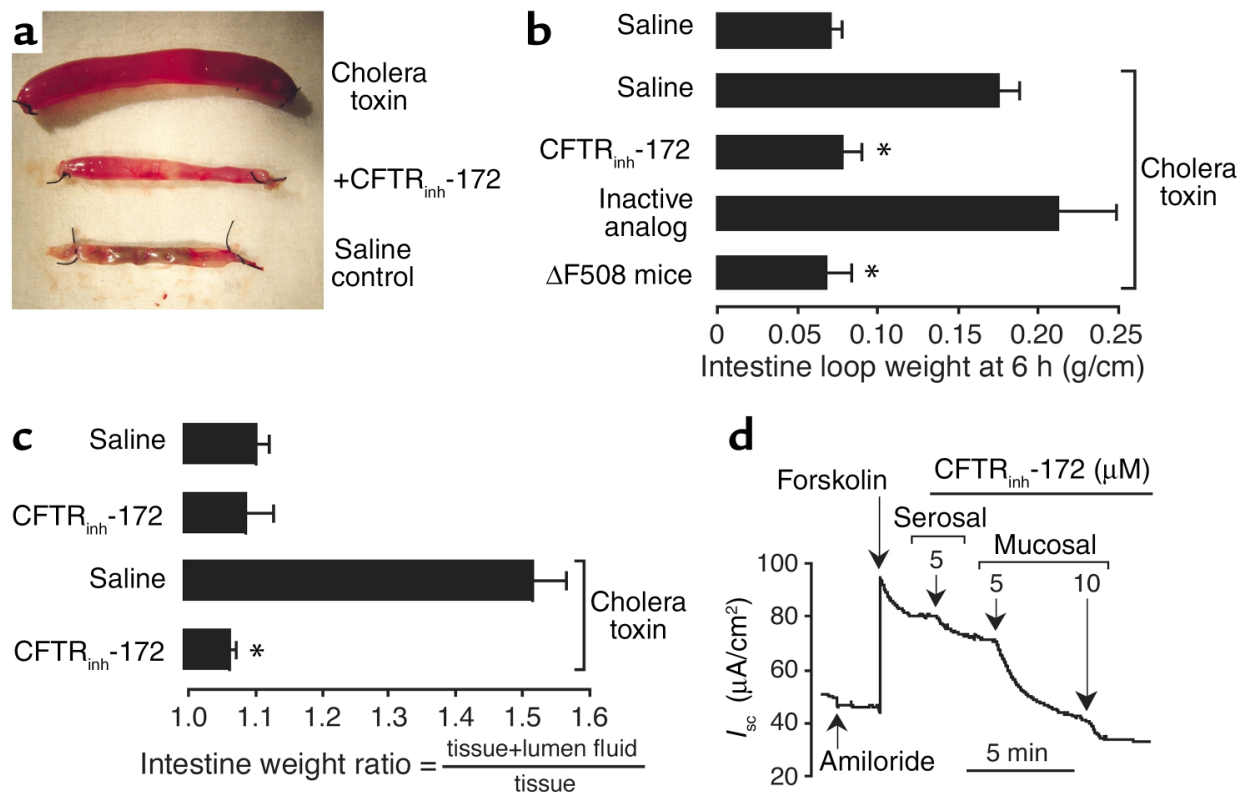

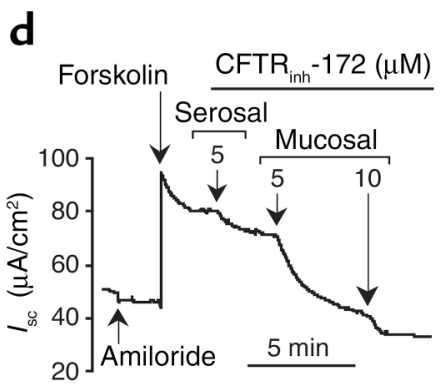

\section{Figure 5}

Inhibition of intestinal fluid secretion. (a) Photograph of isolated mouse ileal loops at 6 hours after lumenal injection of $1 \mu \mathrm{g}$ cholera toxin without (top) and with (middle) intraperitoneal injection of CFTR inh-172 (250 $\mu \mathrm{g} / \mathrm{kg})$. Saline control (no cholera toxin) is shown for comparison (bottom). (b) Ileal loop weight at 6 hours. Mean \pm SE $(n=6-8$ mice) with 14-16 loops studied. For the inactive analog, the 4-carboxyphenyl substituent in CFTR inh-172 $_{1}$ was replaced by 3-methoxy-4-methoxyvinylphenyl (SE; six to eight mice per group; ${ }^{*} P<0.001$, ANOVA). (c) Ratio of weight of entire small intestine at 6 hours after oral gavage before versus after luminal fluid removal (SE; four mice per group; $\left.{ }^{*} P<0.001\right)$. (d) CFTR inh $_{172}$ inhibition short-circuit current after amiloride addition and stimulation by forskolin $(20 \mu \mathrm{M})$ in isolated rat colonic mucosa. CFTR inh $^{-172}$ was added to serosal and then mucosal surfaces as indicated. One experiment typical of four is shown. 
of the role of CFTR in water, salt, and macromolecule secretion by submucosal glands. There is considerable interest but so far little progress in the identification or creation of large-animal models of CF. High-affinity CFTR inhibitors may permit the pharmacological creation of a CF animal model that mimics the human $\mathrm{CF}$ phenotype. A large-animal model of CF would be of great value in elucidating the pathophysiology of initiation and progression of airway disease in $\mathrm{CF}$, and in evaluating the efficacy of CF therapies.

\section{Acknowledgments}

This work was supported by a drug discovery grant from the Cystic Fibrosis Foundation (CFF), and grants HL60288, HL-59198, EB-00415, EY-13574, and DK-35124 from the NIH (to A.S. Verkman). L.J.V. Galietta was supported by the CFF and the Telethon-Italy (GP0296Y01). J.R. Thiagarajah was supported by a CFF fellowship.

1. Grubb, B.R., and Boucher, R.C. 1999. Pathophysiology of gene-targeted mouse models for cystic fibrosis. Physiol. Rev. 79(Suppl.):S193-S214.

2. Wong, P.Y. 1997. CFTR gene and male fertility. Mol. Hum. Reprod. 4:107-110

3. Pilewski, J.M., and Frizzell, R.A. 1999. Role of CFTR in airway disease. Physiol. Rev. 79(Suppl.):S215-S255.

4. Cabantchik, Z.I., and Greger, R. 1992. Chemical probes for anion transporters of mammalian cell membranes. Am. J. Physiol. 262:C803-C827.

5. McDonough, S., Davidson, N., Lester, H.A., and McCarty, N.A. 1994 Novel pore-lining residues in CFTR that govern permeation and openchannel block. Neuron. 13:623-634.

6. Schultz, B.D., Singh, A.K., Devor, D.C., and Bridges, R.J. 1999. Pharmacology of CFTR chloride channel activity. Physiol. Rev. 79(Suppl.):S109-S144.

7. Sheppard, D.N., and Welsh, M.J. 1992. Effect of ATP-sensitive $\mathrm{K}^{+}$channel regulators on cystic fibrosis transmembrane conductance regulator chloride currents. J. Gen. Physiol. 100:573-591.

8. Hongre, A.S., Baro, I., Berthon, B., and Escande, D. 1994. Effects of sulphonylureas on CAMP-stimulated $\mathrm{Cl}^{-}$transport via the cystic fibrosis gene product in human epithelial cells. Pflugers Arch. 426:284-287.

9. Edwards, G., and Weston, A.H. 1993. Induction of a glibenclamide-sensitive $\mathrm{K}^{+}$current by modification of a delayed rectifier channel in rat portal vein and insulinoma cells. Br. J. Pharmacol. 110:1280-1281.

10. Rabe, A., Disser, J., and Fromter, E. 1995. $\mathrm{Cl}^{-}$channel inhibition by glibenclamide is not specific for the CFTR-type $\mathrm{Cl}^{-}$channel. Pflugers Arch. 429:659-662.
11. Yamazaki, J., and Hume, J.R. 1997. Inhibitory effects of glibenclamide on cystic fibrosis transmembrane conductance regulator, swelling-activated, and $\mathrm{Ca}^{2+}$-activated $\mathrm{Cl}^{-}$channels in mammalian cardiac myocytes. Circ. Res. 81:101-109.

12. Jayaraman, S., Haggie, P., Wachter, R., Remington, S.J., and Verkman, A.S. 2000. Mechanism and cellular applications of a green fluorescent protein-based halide sensor. J. Biol. Chem. 275:6047-6050.

13. Galietta, L.J.V., Jayaraman, S., and Verkman, A.S. 2001. Cell-based assay for high-throughput quantitative screening of CFTR chloride transport agonists. Am. J. Physiol. 281:C1734-C1742.

14. Galietta, L.J.V., et al. 2001. Novel CFTR chloride channel activators identified by screening of combinatorial libraries based on flavone and benzoquinolizinium lead compounds. J. Biol. Chem. 276:19723-19728.

15. Ma, T., et al. 2002. High-affinity activators of CFTR chloride conductance identified by high-throughput screening of 60,000 diverse compounds. J. Biol. Chem. 277:37235-37241.

16. Rasola, A., Galietta, L.J.V., Gruenert, D.C., and Romeo, G. 1994. Volumesensitive chloride currents in four epithelial cell lines are not directly correlated to the expression of the MDR-1 gene. J. Biol. Chem. 269:1432-1436.

17. Oi, H., et al. 2002. Identification in traditional herbal medications and confirmation by synthesis of factors that inhibit cholera toxin-induced fluid accumulation. Proc. Natl. Acad. Sci. USA. 99:3042-3046.

18. Gorbach, S.L., Banwell, J.G., Chatterjee, B.D., Jacobs, B., and Sack, R.B. 1971. Acute undifferentiated human diarrhea in the tropics. I. Alterations in intestinal microflora. J. Clin. Invest. 50:881-889.

19. Richardson, S.H., and Kuhn, R.E. 1986. Studies on the genetic and cellular control of sensitivity to enterotoxins in the sealed adult mouse model. Infect. Immun. 54:522-528.

20. Gabriel, S.E., et al. 1999. A novel plant-derived inhibitor or cAMP-mediated fluid and chloride secretion. Am. J. Physiol. 276:G58-G63.

21. Aguilar-Bryan, L., and Bryan, J. 1999. Molecular biology of adenosine triphosphate-sensitive potassium channels. Endocr. Rev. 20:101-135.

22. Gabriel, S.E., Brigman, K.N., Koller, B.H., Boucher, R.C., and Stutts, M.J 1994. Cystic fibrosis heterozygote resistance to cholera toxin in the cystic fibrosis mouse model. Science. 266:107-109.

23. Snyder, J.D., and Merson, M.H. 1982. The magnitude of the global problem of acute diarrheal disease: a review of active surveillance data. Bull. World Health Organ. 60:605-613.

24. Chao, A.C., et al. 1994. Activation of intestinal CFTR Cl- channel by heatstable enterotoxin and guanylin via cAMP-dependent protein kinase. ЕМВО J. 13:1065-1072.

25. Kimberg, D.V., Field, M., Johnson, J., Henderson, A., and Gershon, E. 1971. Stimulation of intestinal mucosal adenyl cyclase by cholera enterotoxin and prostaglandins. J. Clin. Invest. 50:1218-1230.

26. Spira, W.M., Sack, R.B., and Froehlich, J.L. 1981. Simple adult rabbit model for Vibrio cholerae and enterotoxigenic Escherichia coli diarrhea. Infect. Immun. 32:739-747.

27. Jayaraman, S., Joo, N.S., Reitz, B., Wine J.J., and Verkman, A.S. 2001. Submucosal gland secretions in airways from cystic fibrosis patients have normal salt and $\mathrm{pH}$ but elevated viscosity. Proc. Natl. Acad. Sci. USA. 98:8119-8123. 